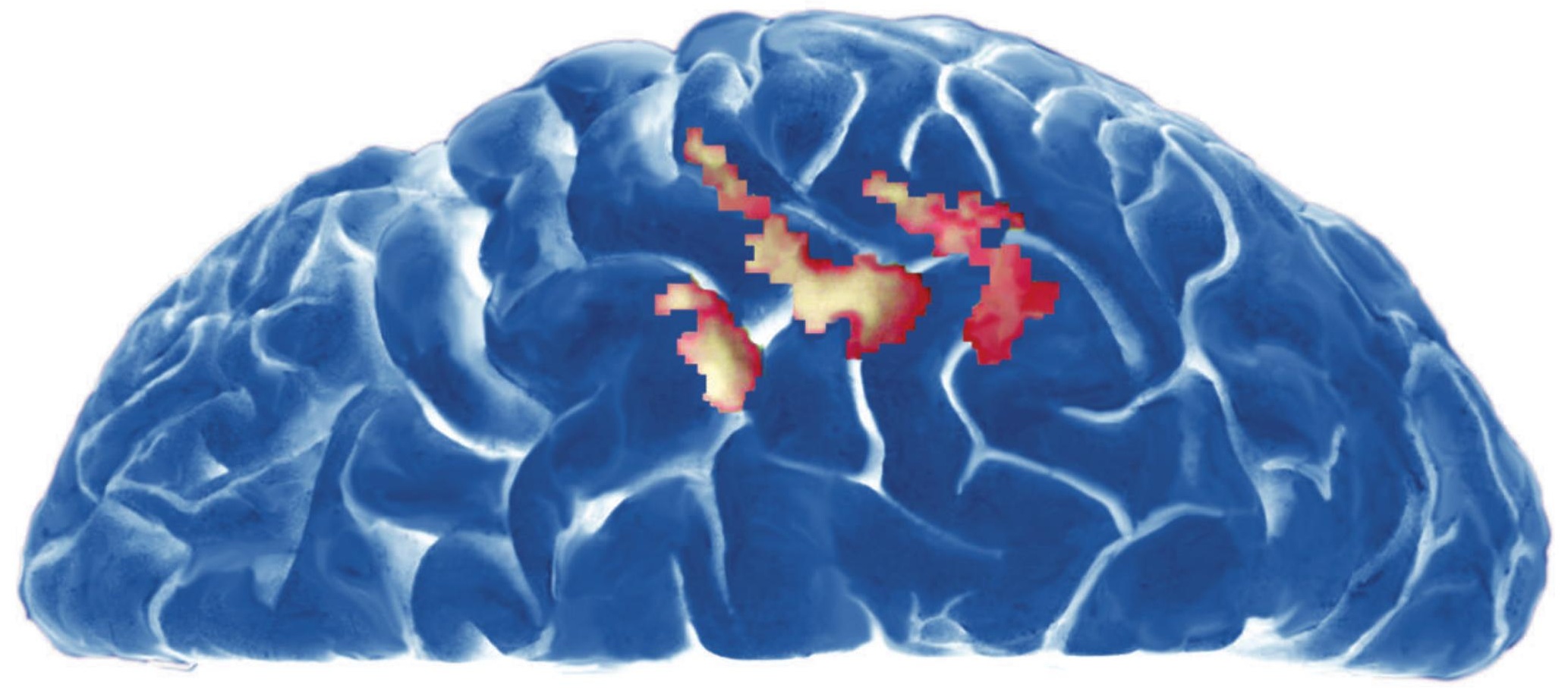

\title{
HEAD CASE
}

\section{Last year, functional magnetic resonance imaging made its debut in court.} Virginia Hughes asks whether the technique is ready to weigh in on the fate of murderers.

2 rian Dugan, dressed in an orange jumpsuit and shackles, shuffled to the door of Northwestern Memorial Hospital in downtown Chicago, accompanied by four sheriff deputies. It was the first time that Dugan, 52, had been anywhere near a city in 20 years. Serving two life sentences for a pair of murders he had committed in the 1980s, he was now facing the prospect of the death penalty for an earlier killing.

Dugan was here on a Saturday this past September to meet one of the few people who might help him to avoid that fate: Kent Kiehl, a neuroscientist at the University of New Mexico in Albuquerque. Dugan, Kiehl and the rest of the entourage walked the length of the hospital, crossed a walkway to another building, and took the lift down to a basement-level facility where researchers would scan Dugan's brain using functional magnetic resonance imaging (fMRI). Todd Parrish, the imaging centre's director, offered plastic zip ties to replace the shackles - no metal is allowed in the same room as the scanner's powerful magnet - but the guards said they weren't necessary. Dugan entered the machine without restraints, and Parrish locked the door - as much to keep the guards and their weapons out as to keep Dugan in.

Dugan lay still inside the scanner for about 90 minutes, performing a series of cognitive control, attention and moral decisionmaking tests. Afterwards he ate a hamburger, sat through an extensive psychiatric interview and rode back to DuPage county jail, about 50 kilometres west of Chicago.

Kiehl has been amassing data on men such as Dugan for 16 years. Their crimes are often impulsive, violent, committed in cold blood and recalled without the slightest twinge of remorse. They are psychopaths, and they are estimated to make up as much as $1 \%$ of the adult male population, and $25 \%$ of male prisoners. To date, Kiehl has used fMRI to scan more than 1,000 inmates, many from a mobile scanner set up in the courtyard of a New Mexico prison. He says that the brains of psychopaths tend to show distinct defects in the paralimbic system, a network of brain regions important for memory and regulating emotion.

\section{Mitigating circumstances}

The purpose of the work, Kiehl says, is to eliminate the stigma against psychopaths and find them treatments so they can stop committing crimes. But Dugan's lawyers saw another purpose. During sentencing for capital crimes, the defence may present just about anything as a mitigating factor, from accounts of the defendant being abused as a child to evidence of extreme emotional disturbance. Kiehl's research could offer a persuasive argument that Dugan is a psychopath and could not control his killer impulses. After reading about Kiehl's work in The New Yorker,
Dugan's lawyers asked Kiehl to testify and offered him the chance to scan the brain of a notorious criminal. Kiehl agreed and Dugan's case became what is thought to be the first in the world to admit fMRI as evidence. Kiehl's decision has put him at odds with many in his profession, and stirred debate among neuroscientists and lawyers.

"It is a dangerous distortion of science that sets dangerous precedents for the field," says Helen Mayberg, a neurologist at Emory University School of Medicine in Atlanta, Georgia. Mayberg, who uses brain imaging to study depression, has testified against the use of several kinds of brain scan in dozens of cases since 1992. Although other brain-imaging techniques have been used in court, it is especially hard to argue that fMRI should be, argue critics. The technique reveals changes in blood flow within the brain, thought to correlate with brain activity, and it has become popular in research. But most fMRI studies are small, unreplicated and compare differences in the average brain activity of groups, rather than individuals, making it difficult to interpret for single cases. It is rarely used in diagnosis. Moreover, a recent scan, say some critics, wouldn't necessarily indicate Dugan's mental state when he committed his crimes.

In 1983, Dugan kidnapped 10-year-old Jeanine Nicarico, of Naperville, Illinois. He raped 
her in the back seat of his car and beat her to death. In 1984, he saw a 27 -year-old nurse waiting at a stop light on a deserted road. He rammed into her car, raped her and drowned her in a quarry. A year later, he plucked a 7-year-old girl from her bicycle, raped her, killed her and left her body in a drainage ditch, weighed down with rocks.

\section{Plea bargaining}

Police charged Dugan with the third murder three weeks after it happened and listed him as a suspect in the nurse's death. Through his lawyers, Dugan offered to confess to all three killings, but only if prosecutors took the death penalty off the table. Authorities, deeming some of Dugan's statements on the Nicarico murder to be unreliable, wouldn't negotiate. One reason for their reluctance was that two men had already been sent to death row for killing Nicarico.

But more than ten years later the two convicted men were finally exonerated. With constituents demanding justice for Nicarico, local authorities used DNA evidence to link Dugan to the crime in 2002. In July last year, he formally pleaded guilty. It was a high-profile case for the area, and local media accounts depict a community haunted by the girl's death. The defence lawyers knew that they would have a tough time arguing for leniency. They were willing to try anything, including the latest that neuroscience could offer.

Brain imaging has a long history in legal cases. Lawyers have often used scans as a way to tip the scale in the perpetual battle between opposing expert psychiatric witnesses. You can't control your brain waves, the theory goes, and scans are an objective measure of mental state. "The psychiatric diagnosis is still soft data it's behaviour," notes Ruben Gur, director of the Brain Behavior Center at the University of Pennsylvania in Philadelphia. "The brain scan doesn't lie. If there is tissue missing from

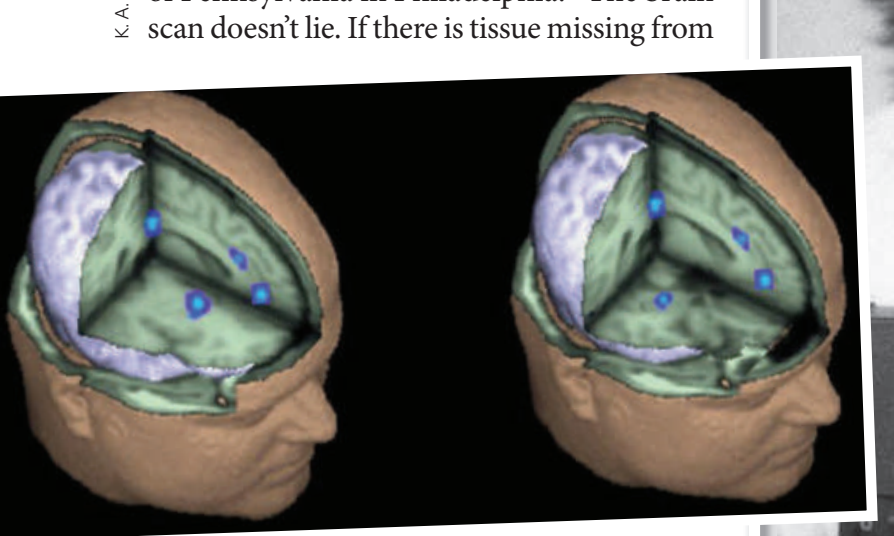

your brain, there is no way you could have manufactured it for the purpose of the trial."

Brain imaging played into the 1982 trial of John Hinckley Jr, who had attempted to assassinate US President Ronald Reagan. Lawyers presented a computed tomography X-ray scan of his head, arguing that it showed slight brain shrinkage and abnormally large ventricles, indicating a mental defect. The prosecution's expert witnesses said the scans looked normal. Whether imaging influenced the verdict is not known, but Hinckley was found not guilty by reason of insanity.

Over the next decade, lawyers gradually switched to positron emission tomography (PET), which can be used to give a measure of metabolic activity in the brain. Gur's research team has scanned dozens of patients with mental illness and hundreds of healthy volunteers using PET and structural MRI - a technique that looks at the static structure of the brain and is more established for diagnosis than fMRI. Through his research, he has developed algorithms that can predict whether a person has schizophrenia, for example, from structural MRI alone with about $80 \%$ accuracy $^{1}$. Gur has testified in roughly 30 criminal cases on behalf of defendants alleged to have schizophrenic or brain-damage.

"We determine whether the values are normal or abnormal," Gur says. "It's a challenge to explain that to a jury, but when they

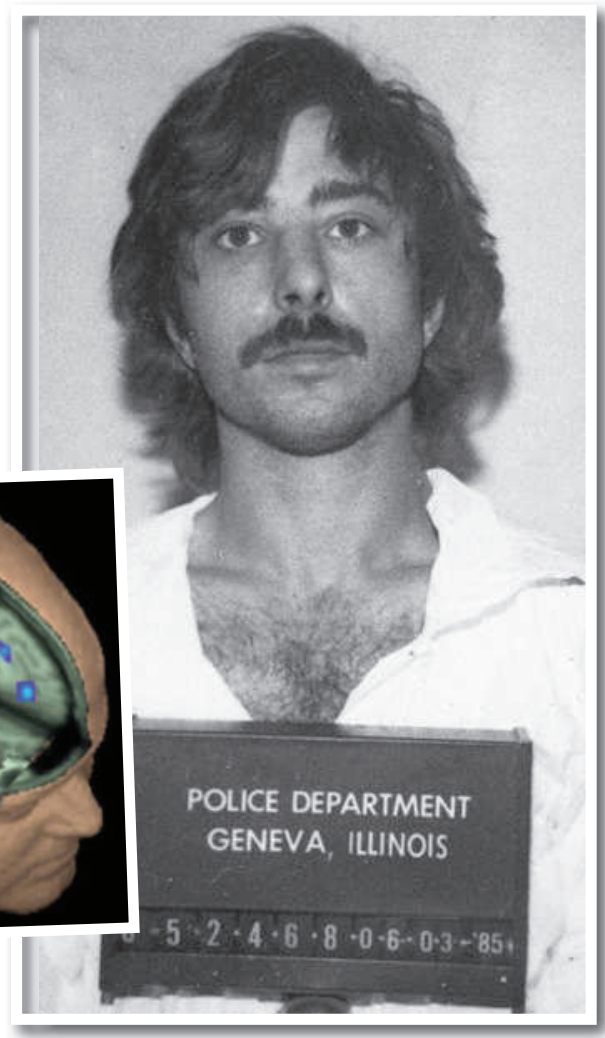

ove: criminal psychopaths show less activity than non-criminal control subjects in specific emotion-processing areas of the brain, according to Kent Kiehl's testing. Right: Brian Dugan in 1985. understand, basically all I'm telling them is that this is not someone who's operating with a full deck. And so, they may not be eligible for the harshest punishment possible." Gur gets so many requests to testify that he has a team of psychology residents and interns to vet them. Still, he doesn't think that fMRI is reliable enough for legal settings. "If somebody asked me to debunk an fMRI testimony, it wouldn't be too hard," Gur says.

That's mainly because fMRI studies deal in average differences between groups. For example, Kiehl's work has shown that when processing abstract words, psychopathic prisoners have lower activity in some brain regions than non-psychopathic prisoners and non-prisoners. But there's bound to be overlap. He has not shown, for example, that any one person showing a specific brain signature is guaranteed, with some per cent certainty, to be a psychopath or behave like one.

For Kiehl, the scan is just part of the picture and he conducts extensive interviews to determine a diagnosis of psychopathy. "It's just one bit of information that helps us understand brain function," he says.

\section{Taking the stand}

On 29 October, Kiehl participated in a 'Frye hearing' for Dugan's case. Based on a 1923 ruling, the hearing determines whether scientific evidence is robust enough to be admitted. Joseph Birkett, the lead prosecutor in the Dugan case, argued that allowing the scans the bright colours and statistical parameters of which are chosen by the researchers - might bias the jury. Some studies, prosecutors argued, have shown that neuroscientific explanations can be particularly seductive to the layperson ${ }^{2}$.

The judge ultimately "cut the baby in half", says Birkett. He ruled that the jury would not be allowed to see Dugan's actual brain scans, but that Kiehl could describe them and how he interpreted them based on his research.

On 5 November, Kiehl took the stand for about six hours. He described the findings of two, three-hour psychiatric interviews with Dugan. Dugan had scored 38 out of a possible 40 on the Hare Psychopathy Checklist, which evaluates 20 aspects of personality and behaviour through a semi-structured interview. (It was developed by Kiehl's graduate-school mentor, Robert Hare.) That puts him in the 99.5th percentile of all inmates, Kiehl says.

Using PowerPoint slides of bar graphs and cartoon brains - but not the scans - Kiehl testified that Dugan's brain, like those of psychopaths in his other studies ${ }^{3}$, showed decreased levels of activity in specific areas. Prosecutors, Kiehl says, went to great lengths to sow confusion about the data. 
At one point during Kiehl's testimony, he showed a cartoon brain with Xs marked on various regions, to illustrate where Dugan's activity was aberrant. The prosecutor, Kiehl recalls, "asked me on cross examination, 'Are there really Xs in this guy's brain?' It's the adversarial system - they were just out to make it look like nothing made sense."

The next day, the prosecution brought a rebuttal witness: Jonathan Brodie, a psychiatrist at New York University. He refuted the imaging evidence on several grounds.

First, there was timing: Kiehl scanned Dugan 26 years after he killed Nicarico. It was impossible to know what was going on in Dugan's brain while he was committing the act, and it was perhaps not surprising that his brain would look like a murderer's after committing murder. Second, Brodie said, there was the issue with

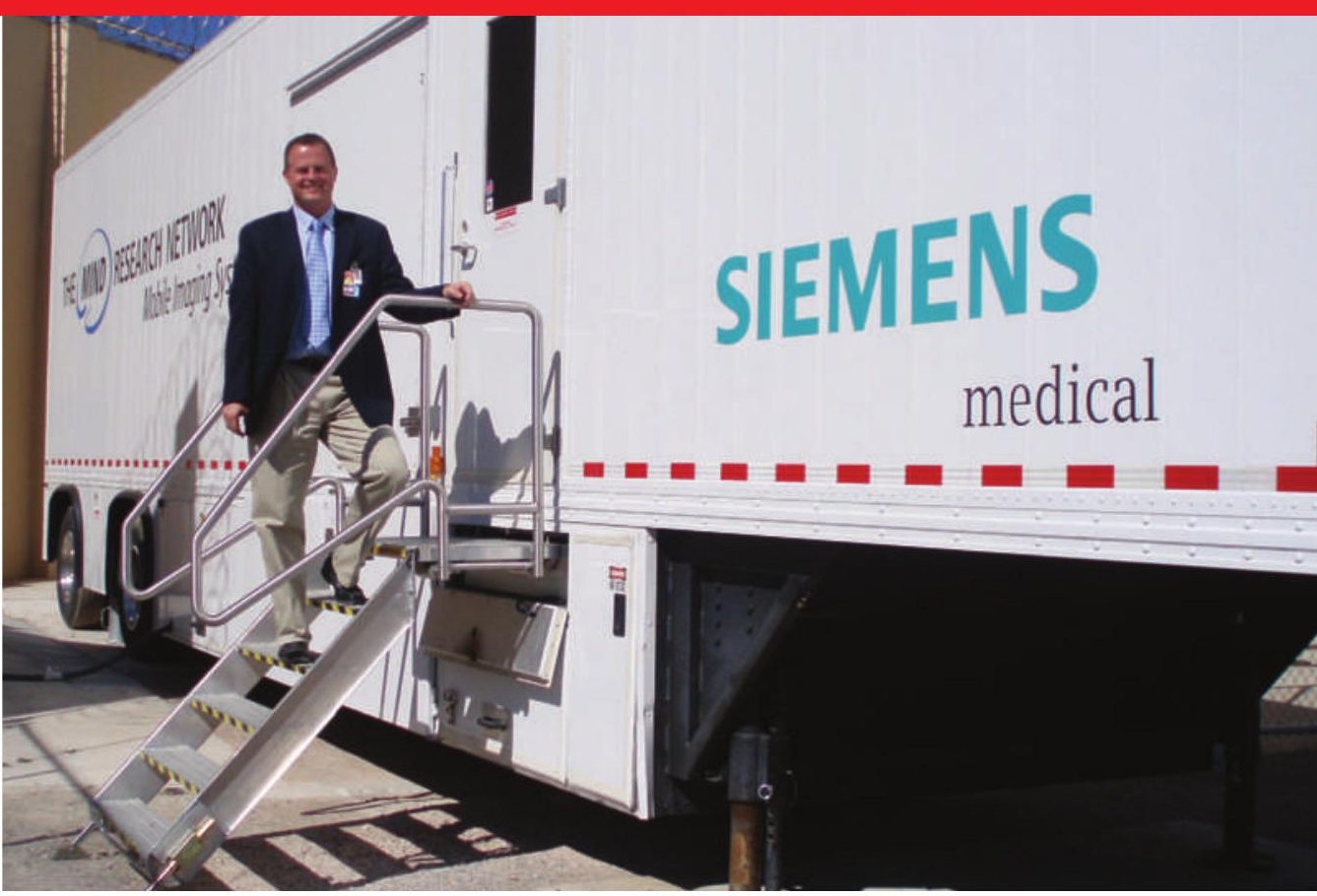

Kent Kiehl outside the mobile scanner he has used to look at the brains of inmates at a New Mexico prison. average versus individual differences. If you look at professional basketball players, most of them are tall, he told the jury, but not everyone over six foot six is a basketball player.

From a technical perspective, Kiehl's work is expertly done, says Brodie. "I have no issue with his science. I have an issue with what he did with it. I think it was just a terrible leap."

Even if fMRI could reliably diagnose psychopathy, it wouldn't necessarily reduce a defendant's culpability in the eyes of a judge or jury. Ultimately, the law is based on an individual's rational, intentional action, not brain anatomy or blood flow, says Stephen Morse, professor of law and psychiatry at the University of Pennsylvania. "Brains don't kill people. People kill people," says
"Kiehl got a lot of criticism, but I think what he did is perfectly reasonable." says Steve Greenberg, Dugan's lawyer. The switched verdict will definitely be brought up in the appeal to the state supreme court, says Greenberg, as will the fact that the jurors weren't allowed to see Dugan's brain scans.

Since November, Kiehl says he has been contacted by about a dozen lawyers asking for similar services. In February, he and Parrish scanned another man on trial using the same fMRI scanner at Northwestern Memorial Hospital. For Kiehl the motivations for scanning Dugan were twofold. "It gave me an opportunity to study one of the classic psychopaths in American history," he says. That included privileged access to Dugan and his massive case file.

Kiehl also says he feels a "moral obligation" to help educate the Morse, who also co-directs the MacArthur Foundation's Law and Neuroscience Project, which brings together scientists, lawyers and judges to debate how brain technology should be used in legal settings.

\section{Change of heart}

Dugan's sentencing proceedings ended four days after Brodie's testimony. The jury deliberated for less than an hour before coming back with a verdict: ten for the death penalty and two for life in prison - a death sentence requires a unanimous vote.

But while waiting for the Nicarico family to return to the courtroom, one of the jurors asked for more time and the judge agreed. The jury asked for copies of several transcripts of testimony, including Kiehl's, and went back into deliberation. The next day, all 12 jurors voted to send Dugan to his death.

Even with the unfavourable final verdict, Kiehl's testimony "turned it from a slam dunk for the prosecution into a much tougher case", jury, and the public, about psychopathy, a disorder that is often maligned in the popular press. "You can live in the ivory tower for your whole career, and never really have a practical influence. This was a chance to help," says Kiehl.

Many of his peers are unimpressed. The witness stand, says Mayberg, is "not a soapbox".

"What you might believe to drive your own research is very different from being a spokesperson for science," she says, adding that people who take the stand should not use the platform as a way to meet their own scientific agenda.

Others are less critical. When DuPage county prosecutors discovered that Dugan's defence team would be using brain imaging, they contacted Scott Grafton, director of the Brain Imaging Center at the University of California, Santa Barbara. Grafton has testified against imaging in many cases, but this time he declined, saying that even potentially shaky scientific evidence should be allowed during the sentencing phase of a trial.
"Kiehl got a lot of criticism, but I think what he did is perfectly reasonable," says Grafton. "I've had judges tell me, 'Look, everything else everybody's bringing into a mitigation hearing is extremely unreliable, so why should we hold scans to a different standard?"”

Whatever standards fMRI scans should be held to, neuroscientists and the legal system are under pressure to work them out fast. Although a fledgling technology, fMRI has been knocking at the doors of the courts for a while. Since at least 2007, two US companies, Cephos in Tyngsboro, Massachusetts, and No Lie MRI in San Diego, California, have been selling 'deception detection' services based on fMRI scans. The technology has almost certainly been used in plea bargains (like its older cousin, the polygraph), and is expected to debut in court within a few years. Use of fMRI for diagnosing mental disorders, as was the case for Dugan, will improve and more scans will probably show up in court, says Gur. "That's only a question of time."

What matters, though, is how the jury perceives the evidence and the testimony - and in Dugan's case, it's not clear how much weight it carried. For Michael Euringer, a juror in the trial and a retired stockbroker, it didn't mean much at all. "I don't think that they were able to present that idea that he had a brain defect. $\mathrm{He}$ was a psychopath, but he was not psychotic," he says. "But it all depends on the jury."

Virginia Hughes is a freelance writer in New York City.

\footnotetext{
Davatzikos, C. et al. Arch. Gen. Psychiatry 62, 1218-1227 (2005)

2. Weisberg, D. S., Keil, F. C., Goodstein, J., Rawson, E. \& Gray, J. R. J. Cogn. Neurosci. 20, 470-477 (2008)

3. Kiehl, K. A. et al. Psychiatry Res. 130, 297-312 (2004)
}

See Editorial, page 325; News Features, pages 344 and 347; Opinion, page 351; and online at www.nature.com/scienceincourt. 